\title{
REVISION OF FAILED KNEE REPLACEMENTS USING FIXED-AXIS HINGES
}

\author{
A. E. INGLIS, P.S. WALKER
}

From the Institute of Orthopaedics, Stanmore

\begin{abstract}
Forty failed hinged arthroplasties of the knee were revised by the insertion of another hinged implant. In 14 cases the prosthesis used at the revision operation was similar to the primary implant; in 26, a hinge with an elongated femoral stem was used, usually replacing part of the femoral shaft. In seven of these knees an elongated tibial stem was also required, though the tibial shaft was replaced in only two of them. There were many complications. Fracture of the femur at the tip of the femoral stem was the most frequent.

Sixteen first revisions failed and were revised a second time; 12 required replacement of the distal femoral shaft and three required replacement of the proximal tibia. The incidence of complications in knees requiring a second revision was even higher. Four required a third revision after an average interval of three years.
\end{abstract}

Failure of a hinged prosthesis results in bone loss mainly in the femur. Revision of a failed hinged prosthesis with another of the same design is unlikely to be successful and may cause fracture of the femur.

Many of the failed total knee prostheses revised in recent years were originally inserted during the 1970 s and early 1980s when fixed hinges, intercondylar linked designs and early types of condylar replacements were used. Condylar replacements can usually be revised using another condylar design, with thicker components and possibly short stems to augment fixation. However, the revision of hinges and other designs with cemented intramedullary stems presents a more difficult problem.

The fixed hinges evidently had a lower failure rate than did some of the early condylar prostheses, despite the more serious nature of the cases in which they were used. For example, the Stanmore hinge (Biomet, Bridgend, Wales) gave an $80 \%$ survival rate at seven years (Grimer, Karpinski and Edwards 1984); in a two to eight year follow-up, there was an $8.5 \%$ revision rate and a cumulative success rate of $83 \%$ at seven years (Lettin et al 1984). Seven of 11 cases followed up for more than ten years showed no deterioration from their status at one year (Lettin, Kavanagh and Scales 1984). In a large series of Blauth intercondylar hinges, there was an $89 \%$ probability of survival at ten years (Hassenpflug et al

A. E. Inglis Jr, MD, Consultant Orthopaedic Surgeon

St Luke's Hospital, New York, NY, USA.

P. S. Walker, PhD, Professor of Biomedical Engineering Department of Biomedical Engineering, Institute of Orthopaedics, Royal National Orthopaedic Hospital, Stanmore, Middlesex HA7 4LP, England.

Correspondence should be sent to Professor P. S. Walker.

(C) 1991 British Editorial Society of Bone and Joint Surgery

$0301-620 X / 91 / 5210 \$ 2.00$

J Bone Joint Surg [Br] 1991 ; 73-B: 757-61.
1988). However, the serious nature of the failures, which include infection, loosening with substantial bone loss, fracture of the femur at the stem tip, and instability due to ligament resection, are well known.

Though there have been few studies of revision arthroplasty of the knee, it is apparent that they have been much less successful than primary procedures. Of 76 revisions in patients with rheumatoid arthritis, using a variety of prostheses, 21 had failed after five years (Rööser et al 1987). In a series of 38 rotating hinges, progressive radiolucent lines were seen in only three of 15 primary cases but in ten of 23 revisions (Rand, Chao and Stauffer 1987). Shaw, Balcom and Greer (1989) reported similar results.

Using the Total Condylar III prosthesis (Johnson \& Johnson, Braintree, Massachusetts, USA), Donaldson et al (1988) reported no failures at an average of 3.8 years in 17 primary replacements, and five failures in 14 revisions. When the Stanmore hinge was used in 52 revisions, the worst results were found after revising the most bulky and invasive devices (Karpinski and Grimes 1987). We report the results of revising such cases, using fixed hinges with distal femoral or proximal tibial replacements where necessary.

\section{METHODS AND RESULTS}

We included in the study all cases referred to the Biomedical Engineering Department in which a Stanmore hinged prosthesis had been employed for a revision arthroplasty, and which had been followed up for a minimum of two years.

There were 60 revisions in 57 patients; ten knees in 
ten patients were lost to follow-up, and in another ten knees the data was inadequate, leaving 40 knees (37 patients) in the study group.

The prostheses used at the primary operation are listed in Table I. The Stanmore hinge predominated because it had been used extensively in our hospital.

At follow-up, three patients had died, 21 prostheses were still in place and 16 had had a second revision. Of these, three patients had died, nine prostheses were still in place and four had needed a third revision, all of which were still functioning. The times of follow-up are shown in Table II.

The type of prosthesis used for the first revision is shown in Figure 1. In most there was either complete

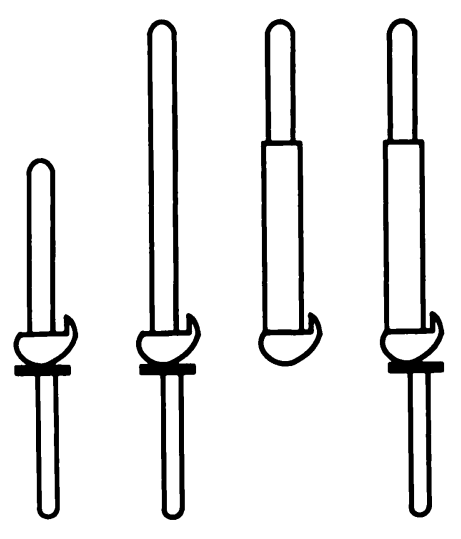

13 1 14

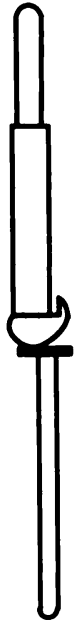

Fig. 1

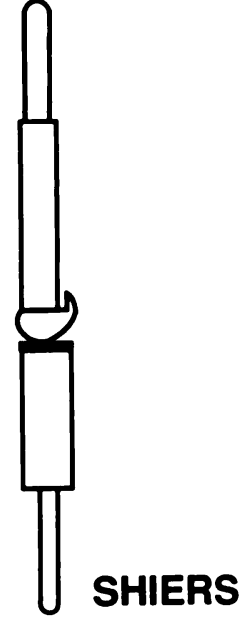

1

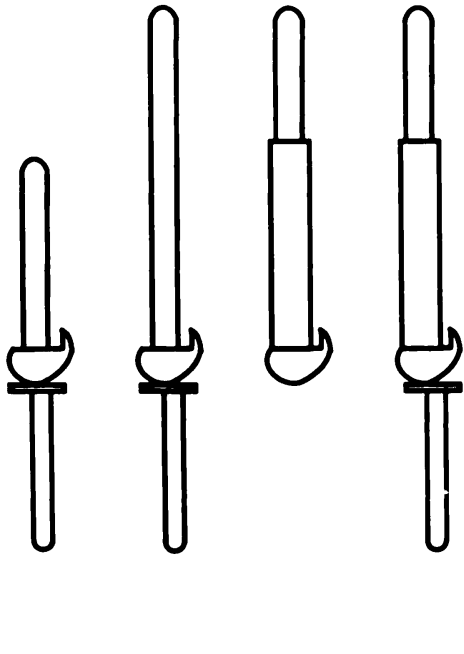

2

1

5
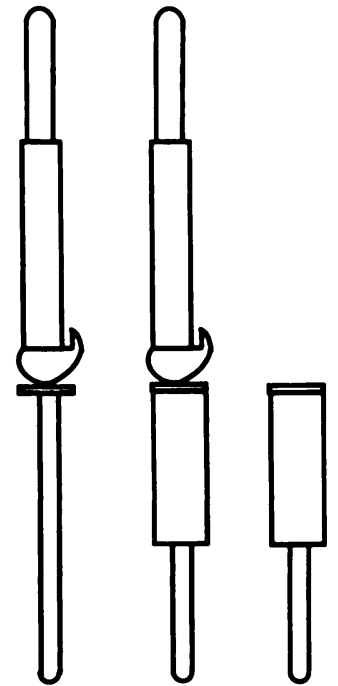

2

3

2 1

Diagrammatic representation of the Stanmore hinged designs used in the $\mathbf{4 0}$ first revisions.

Fig. 2

Components used in the 16 second revisions.

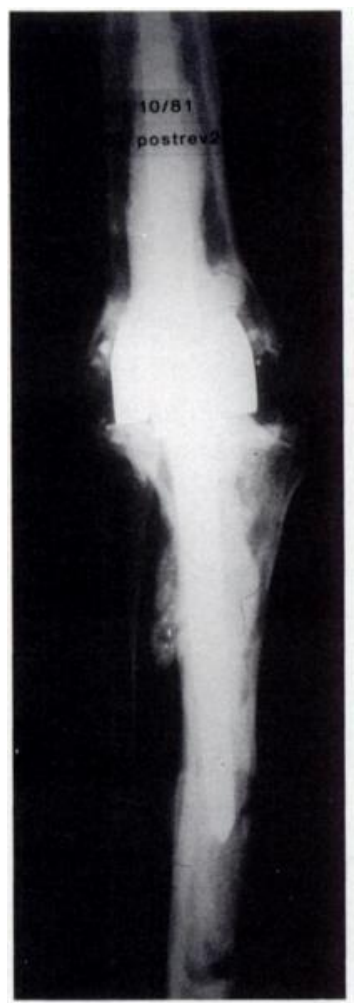

Fig. 3a

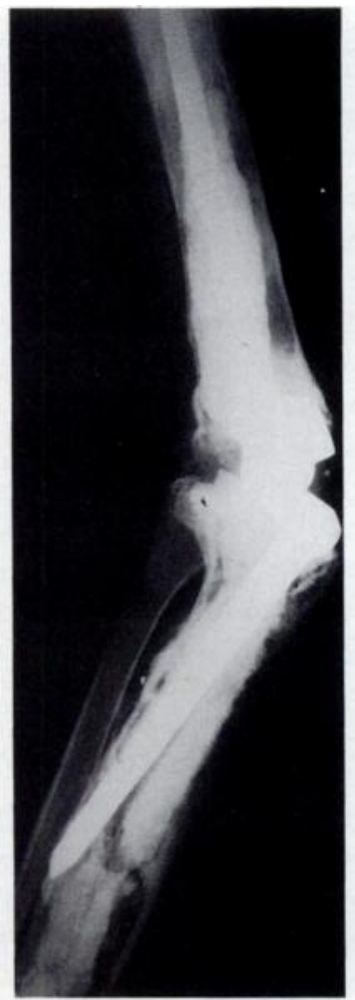

Fig. 3b

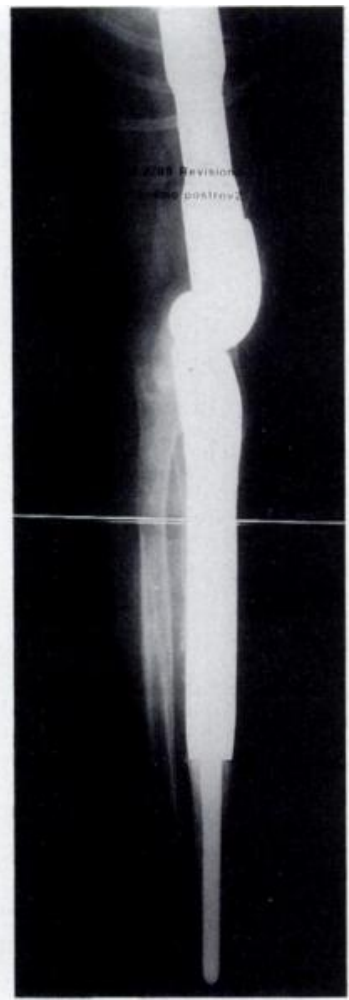

Fig. 3c
This knee had been treated primarily with a Stanmore hinge for severe varus deformity and instability. Following failure due to loosening, another hinge was implanted with cement. This failed due to loosening and tibial fracture (a and $b$ ). The second revision was by prosthetic replacement of the distal femur and the proximal tibia (c). It was functional at the time of review. 
Table I. Number and types of prosthesis used at the primary operation in 40 knees later revised

\begin{tabular}{lr}
\hline Stanmore & 25 \\
Attenborough & 4 \\
Shiers & 3 \\
Freeman-Swanson Mk 1 & 2 \\
Geomedic & 2 \\
Sheehan & 2 \\
Guépar & 1 \\
Walldius & 1 \\
\hline
\end{tabular}

Table II. Follow-up times after the first and subsequent revisions

\begin{tabular}{lll}
\hline & $\begin{array}{l}\text { Mean } \\
\text { (years) }\end{array}$ & $\begin{array}{l}\text { Range } \\
\text { (years) }\end{array}$ \\
\hline After first revision & 4.5 & 0.9 to 10.2 \\
After second revision & 3.0 & 0.0 to 8.3 \\
After third revision & 1.4 & 0.3 to 2.2 \\
\hline
\end{tabular}

Table III. Complications following the first revision

\begin{tabular}{lr}
\hline Femoral fractures around stem & 13 \\
Intra-operative femoral fracture & 1 \\
Tibial fractures around stem & 2 \\
Shortening $>60 \mathrm{~mm}$ & 1 \\
Patellar ligament rupture & 1 \\
Infection (3 previous, 5 new) & 8 \\
Interval operations & \\
$\quad$ Open reduction, fixation of femoral fracture & 4 \\
Removal of cement debris & 1 \\
\hline
\end{tabular}

Table IV. The extent and site of radiolucent lines more than $1 \mathrm{~mm}$ thick in the $\mathbf{4 0}$ first revisions

\begin{tabular}{llll}
\hline & \multicolumn{3}{l}{ Femur } \\
\cline { 2 - 4 } Tibia & None & $<\mathbf{5 0 \%}$ & $>\mathbf{5 0 \%}$ \\
\hline None & 1 & 3 & 13 \\
$<50 \%$ & 1 & 4 & 3 \\
$>50 \%$ & 1 & 2 & 12 \\
\hline
\end{tabular}

Table V. Complications following the second revision

\begin{tabular}{lr}
\hline Femoral fractures around stem & 4 \\
Intra-operative femoral fracture & 1 \\
Tibial fractures around stem & 1 \\
Infection (5 previous, 2 new) & 7 \\
Interval operations & 1 \\
$\begin{array}{l}\text { Open reduction, fixation of femoral fracture } \\
\text { Removal of proximal end of femur stem }\end{array}$ & 1 \\
\hline
\end{tabular}

replacement of the Stanmore hinge, or a distal femoral replacement was used and fitted to the existing tibial component. The distribution of types reflects the higher incidence of loosening of the femoral component than of the tibial. If there was serious endosteal bone loss in the distal femur, or a united fracture at the tip of the stem, a distal femoral replacement was usually chosen.

Following the first revision, there were many complications, fracture of the femur and infection being the most frequent (Table III).

When we reviewed the first revisions, an estimate was made of the percentage of the cement-bone interfaces which showed $1 \mathrm{~mm}$ or thicker radiolucent lines, indicative of bone resorption and a tendency to loosen. Most cases showed radiolucency along more than $50 \%$ of the femoral interface, and most of these also had radiolucency of greater than $50 \%$ at the tibial interfaces (Table IV).

When a second revision was required, distal femoral replacement was needed in two-thirds of the cases, and only two were revised with standard hinges (Fig. 2). In three knees, proximal tibial replacement components were used, necessitating destruction of the quadriceps insertion. The incidence of complications in these 16 cases was even higher than after the first revision; $25 \%$ had fractures around the femoral stem and $44 \%$ became infected (Table V). The incidence of radiolucency was again high and in only three cases was no radiolucency observed. In four cases, there was more than $50 \%$ radiolucency on the femoral side and in five more there was more than $50 \%$ at both the femoral and the tibial interfaces. An example of a knee after two revisions is shown in Figure 3.

The 16 primary revisions which failed did so after an average of 4.5 years. The four second revisions which failed did so after an average of three years. The knees which had a third revision, were followed for up to 2.2 years with no further failures.

The failures occurred mainly in patients revised to a standard hinge replacement. Only two knees revised to a distal femoral replacement prosthesis have failed.

\section{DISCUSSION}

A major complication and cause of failure was fracture of the femur at the level of the tip of the intramedullary stem. This was invariably due to the close proximity of the tip to the lateral cortex. Varus moments at the joint must be transmitted to the stems by the fixed axis hinge and lead to a high stress concentration at their tips. When a standard hinge was used for revision, the bone at this site, already weakened, was at the exact location of the revision stem. This complication occurred in $38 \%$ of the first revisions and in $31 \%$ of the second revisions, comprising more than half the failures. It is potentially avoidable by using a centraliser on the ends of the intramedullary stems, to ensure a minimum thickness of cement to distribute the stresses more uniformly. 

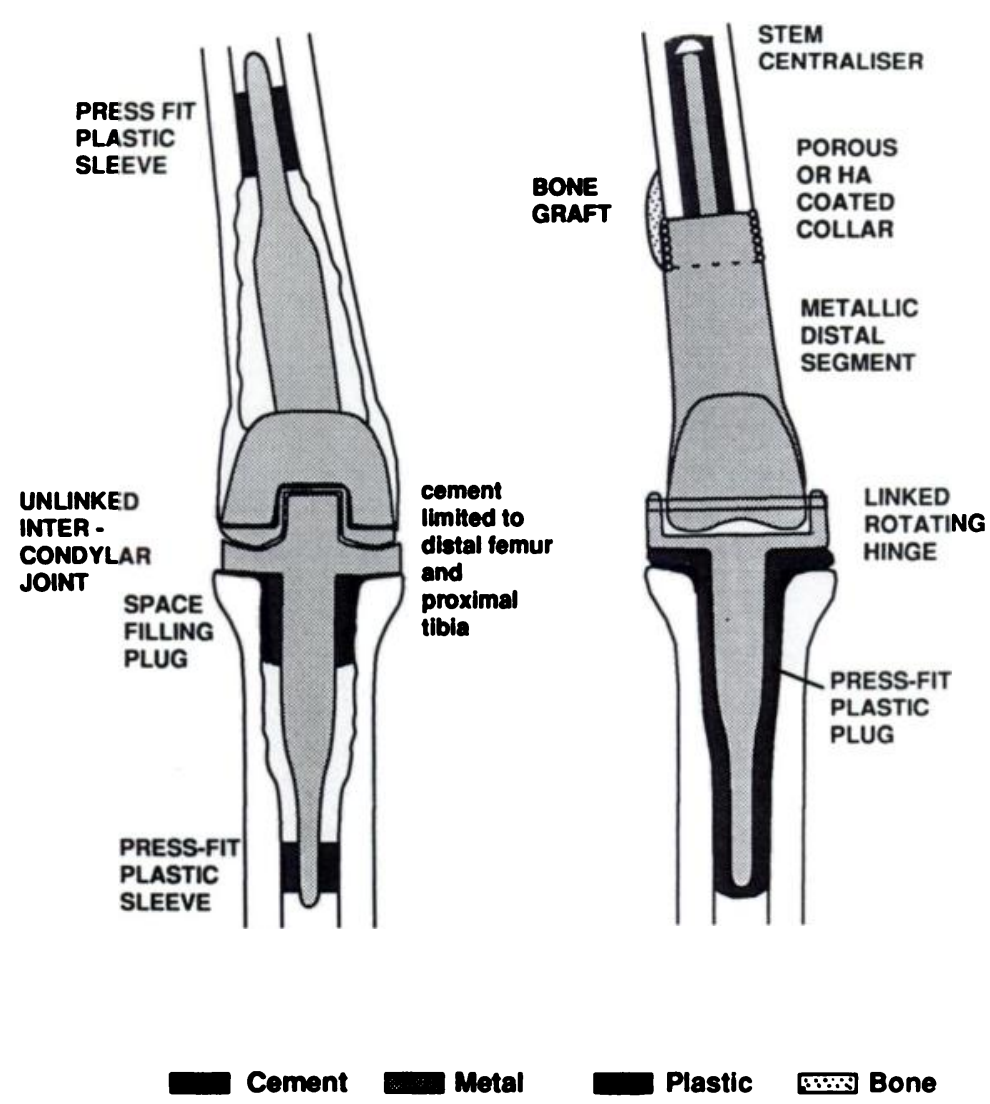

Fig. 4

Designs for revising failed hinged prostheses. They employ non-fixed hinges and are partially cemented.

There was a much higher incidence of extensive cement-bone radiolucency on the femoral side than on the tibial $(60 \%: 38 \%)$. This is probably because of the higher varus bending moment on the femur; the more extensive cancellous fixation of the tibial component may also be a factor.

Two of the complications, infection and loss of endosteal bone stock, are probably inherent in designs which require the cementing of long intramedullary stems. The volume of foreign material and the large surface area of the implant are probably major factors, particularly if loosening occurs with the production of cement and bone debris.

The poor results of revising with a standard hinge can be attributed to the loss of intramedullary bone, and consequent lack of support for a subsequent prosthesis. By contrast, the comparative success of the distal femoral replacements was probably due to cementing the stem more proximally into the strong cortical shaft of the midfemur. If there is an un-united fracture at the tip of the femoral stem, distal femoral replacement may be the only choice. The functional disability with such a prosthesis does not seem to be serious, especially in older patients. On the other hand, proximal tibial replacement gives a poor functional result. Fortunately, in this series, it was seldom required.
Revision of a failed hinge with cemented stems presents a difficult problem and our study suggests that replacement by another hinge, even in an old and sedentary patient, is an unsatisfactory solution. The use of longer stems, extending 50 to $100 \mathrm{~mm}$ beyond the cavity left by the previous stem (the length depending upon the structural integrity of the remaining bone), can provide durable fixation. The diameter of the stem might be increased to fill the space and reduce the amount of cement used. Distal femoral replacement with a cemented intramedullary stem is a reasonable solution if the distal femur has been destroyed. In a recent study of distal femoral replacements after excision of bone tumours in young patients, survivorship at eight years was $86 \%$ (unpublished data). However, proximal tibial replacement is undesirable and a long-stemmed component, enlarged proximally to fill the cavity, enabling quadriceps function to be maintained, might be a better solution.

For patients who are potentially active or who have a longer life expectancy, alternative schemes may be preferable (Fig. 4). The main purpose of an intramedullary stem is to provide resistance to bending in the frontal and sagittal planes. An uncemented stem can be used, supported at its extremity by a tapered plastic plug. The plug centralises the stem, prevents the stress concentration at its stem tip, and spreads the forces over a wider 
area of bone. Such a design has been used in 'growing prostheses' for children after excision of bone tumours (Scales et al 1987). In a radiographic study of 49 implants followed for up to 58 months, there were minimal adverse changes at the plastic-bone interface (Inglis et al 1991). In order to provide resistance to torsion, the region adjacent to the joint can be provided with maximum contact area and cemented, in the manner described by Bertin et al (1985).

Unlimited hinges which allow some anteroposterior and rotational freedom can be used and, while there is no clinical evidence that non-fixed-axis hinges result in less loosening, the torsional stresses along the interfaces, as well as the rate of load transmission, are reduced.
Finally, large areas of bone loss can be dealt with by spacers. These can be simple blocks to make up for lost length, or conical forms to fill the cavities left after removal of stemmed prostheses. Uncemented or partially cemented designs have the advantage that they are compatible with bone grafting and with efforts to stimulate new bone growth. Our study suggests that it is necessary to restore bone stock if revision operations are to have lasting success in these difficult cases.

No benefits in any form have been received or will be received from a commercial party related directly or indirectly to the subject of this article.

\section{REFERENCES}

Bertin KC, Freeman MAR, Samuelson KM, Ratcliffe SS, Todd RC. Stemmed revision arthroplasty for aseptic loosening of total knee replacement. J Bone Joint Surg [ Br] 1985; 67-B :242-8.

Donaldson WF III, Sculco TP, Insall JN, Ranawat CS. Total condylar III knee prosthesis. Clin Orthop 1988; 226:21-8.

Grimer RJ, Karpinski MRK, Edwards AN. The long-term results of Stanmore total knee replacements. J Bone Joint Surg [Br] 1984; 66-B: $55-62$.

Hassenpflug J, Harten K, Hahne HJ, et al. Ist die implantation von kniegelenkscharnierendoprothesen heute noch vertretbar? 15 jahre erfahrungen mit der kniegelenkendoprothese nach blauth. $Z$ Orthop 1988; $126: 398-407$.

Inglis Jr AE, Walker PS, Sneath RS, Grimer R. Uncemented intramedullary fixation of implants using polyethylene sleeves. Clin Orthop 1991 : in press.

Karpinski MRK, Grimer RJ. Hinged knee replacement in revision arthroplasty. Clin Orthop 1987; 220:185-91.
Lettin AWF, Kavanagh TG, Craig D, Scales JT. Assessment of the survival and the clinical results of Stanmore total knee replacements. J Bone Joint Surg [Br] 1984; 66-B:355-61.

Lettin AWF, Kavanagh TG, Scales JT. The long-term results of Stanmore total knee replacements. J Bone Joint Surg [Br] 1984; 66-B:349-54.

Rand JA, Chao EYS, Stauffer RN. Kinematic rotating-hinge total knee arthroplasty. J Bone Joint Surg [Am] 1987; 69-A :489.

Rööser B, Boegard T, Knutson K, Rydholm U, Lidgren L. Revision knee arthroplasty in rheumatoid arthritis. Clin Orthop 1987; 219:16973.

Scales JT, Sneath RS, Wright KWT. Design and clinical use of extending prostheses. In: Enneking WF, ed. Limb salvage in musculoskeletal oncology. Churchill Livingstone, London, 1987: $52-61$.

Shaw JA, Balcom W, Greer RB III. Total knee arthroplasty using the kinematic rotating hinge prosthesis. Orthopedics 1989; $12: 647-54$. 